\section{Use of dexmedetomidine for carotid artery stenting in a patient with multiple comorbidities}

\section{Surya Kumar Dube, Arati Rai', Meyong Pincho Bhutia', Hemanshu Prabhakar}

An 82-year 90-kg male presented with repeated episodes of transient loss of consciousness since 7 days, weakness of left side of body and deviation of mouth to left side of body since 2 days. He was a smoker since last 50 years and was a known case of hypertension and Type 2 diabetes mellitus since last 10 year and chronic obstructive pulmonary disease (COPD) since last 3 years. He had a history of snoring and dyspnoea on exertion New York Heart Association grade 2 and had undergone coronary artery bypass grafting 15 -years ago. He also had a history of hoarseness of voice 4 years ago for which he underwent laryngeal biopsy followed by microlaryngeal surgery (MLS) of a vocal cord nodule. The patient had complaints of mild hoarseness of voice following the laryngeal surgery. His routine haematological investigations were within normal limit. He had COPD changes in chest- $X$ ray and his ECG showed ST depression in the in V3-V5, II and avF leads and right bundle branch block. He had a left

Department of Neuroanaesthesiology, Neurosciences Centre, All India Institute of Medical Sciences, New Delhi, ${ }^{1}$ Department of Anaesthesia, Sikkim Manipal Institute of Medical Sciences, Tadong, Gangtok, Sikkim, India 
ventricular ejection fraction (LVEF) of 50\% with inferior wall regional wall motion abnormality (RWMA) and mild MR in 2D Echocardiography. He was edentulous, having a short neck and with a Mallampatti class (MPC) of 3 . One respiratory system examination he had bilateral rhonchi and occasional crepititions in right lower lung area. He had grade 3 motor power in both left upper and lower extremity without any sensory deficit. Rest of the systemic examination was normal. As the patient was uncooperative pulmonary function test could not be performed. His medications included tab metformin (500 mg), glimeperide (1 mg), aspirin (75 mg), atrovastatin $(20 \mathrm{mg})$, and tab losartan $(50 \mathrm{mg})$ once a day and tab amlodipine $(10 \mathrm{mg})$ twice a day. The patient was also receiving salbutamol and ipratropium inhalation three times a day and as when required. In the magnetic resonance angiography, he had $>90 \%$ stenosis of right carotid artery and $>50 \%$ stenosis of left carotid artery and he was scheduled for right carotid artery stenting (CAS). Since the patient refused for general anaesthesia and direct communication with the patient was desirable for the neuroradiologists, a decision to perform the procedure was scheduled to be performed under conscious sedation (CS).

The patient was advised to take all his scheduled medications (except metformin) before the procedure. We did not premedicate the patient. In the neuroradiological suite all the airway equipments and defibrillator was arranged and all routine monitors were attached. A left radial artery cannulation was performed under local anaesthesia and oxygen was administered through nasal prongs (at $4 \mathrm{l} / \mathrm{min}$ ) along with continuous $\mathrm{ETCO}_{2}$ monitoring. A bolus dose of Dexmedetomidine $(1 \mu \mathrm{g} / \mathrm{kg})$ was administered over 20 mins and the femoral artery puncture sites in both the limbs were infiltrated with $2 \%$ plain lignocaine solution. An infusion of dexmedetomidine was titrated to $0.1 \mu \mathrm{g} / \mathrm{kg}$ (dose that allowed a comfortable patient communicating with the neuroradiologists). Except two episodes of bradycardia and 1 episode of transient hypertension (all during stent placement) which were managed with glycopyrrolate and labetalol, respectively, the patient had stable vitals throughout the procedure. We discontinued the dexmedetomidine infusion approximately 15 mins before the end of the procedure. The patient had a smooth recovery and was shifted to the intensive care unit for observation.

The current recommendations for CAS are for patients with symptomatic severe stenosis $(>70 \%)^{[1]}$ and in patients with other coexisting medical abnormality. CAS is a safe therapeutic option. ${ }^{[2]}$ Local anaesthesia, general anaesthesia or CS are available options for CAS. But profound sedation, airway obstruction and lack of patient cooperation are always a matter of concern during the use of sedative agents (propofol, midazolam, etc.) and use of benzodiazepine and/or opioid is associated with respiratory depression which is commonly seen in older patients and patients with COPD ${ }^{[3]}$ Dexmedetomidine is a selective alpha-2 adrenoreceptor agonist with sedative and analgesic effects. The other advantages of dexmedetomidine are lack of respiratory depression, better patient cooperation during sedation and easy arousal after sedation. ${ }^{[4,5]}$ The lack of respiratory depression and bronchodilatory effects of dexmedetomidine are useful properties which can be useful in patients with COPD. ${ }^{[3]}$ Our patient had complaints of hoarseness of voice which might be due to some of laryngeal pathology which remained undiagnosed due to lack of follow-up after the MLS. So in the settings of COPD in an obese elderly patient with hoarseness of voice, a short neck and MPC of 3 , the importance of lack of respiratory depression of dexmedetomidine cannot be over emphasised.

The reported cardiovascular effects of dexmedetomidine are bradycardia and hypotension which are usually temporary and can be treated with atropine or ephedrine and volume infusion. ${ }^{[3,6]}$ An initial hypertension followed by reflex decrease in heart rate has been described with dexmedetomidine administration and this response can be minimised by administering dexmedetomidine slowly over 10 mins. ${ }^{[7]}$ In our case, we encountered two episodes of bradycardia at the time of carotid stent placement. As bradycardia and hypotension are reported complications of carotid stenting, ${ }^{[8]}$ in our case, the episodes of bradycardia cannot be ascribed to dexmedetomidine infusion as the patient was receiving dexmedetomidine prior to that and there were no such events during that period. Current literature cautions against the use of dexmedetomidine in patients with compromised cardiac status, but our patient had marginally low LVEF. The use of dexmedetomidine has been reported to decrease the incidence of perioperative cardiac events and myocardial ischaemia ${ }^{[9]}$ and animal study has shown decreased myocardial lactate release (direct measure of myocardial ischaemia) due to sympatholytic effect of dexmedetomidine. ${ }^{[10]}$ So we used dexmedetomidine in our patient.

With this case report we want to emphasise upon the fact that dexmedetomidine has various advantages and which can be very useful while managing a patient with various systemic comorbidities.

\section{REFERENCES}

1. Brott TG, Halperin JL, Abbara S, Bacharach JM, Barr JD, Bush RL, et al. ASA/ACCF/AHA/AANN/AANS/ACR/ASNR/CNS/SAIP/SCAI/SIR/ SNIS/SVM/SVS guideline on the management of patients with extracranial carotid and vertebral artery disease: Executive summary. A report of the American College of Cardiology Foundation/American Heart Association Task Force on Practice Guidelines, and the American Stroke Association, American Association of Neuroscience Nurses, American Association of Neurological Surgeons, American College of 
Radiology, American Society of Neuroradiology, Congress of Neurological Surgeons, Society of Atherosclerosis Imaging and Prevention, Society for Cardiovascular Angiography and Interventions, Society of Interventional Radiology, Society of NeuroInterventional Surgery, Society for Vascular Medicine, and Society for Vascular Surgery. Circulation 2011;124:489-532.

2. Yadav JS, Wholey MH, Kuntz RE, Fayad P, Katzen BT, Mishkel GJ, et al. Stenting and angioplasty with protection in patients at high risk for endarterectomy investigators. Protected carotid-artery stenting versus endarterectomy in high-risk patients. N Engl J Med 2004;351:1493-501.

3. Cata JP, Folch E. Dexmedetomidine as sole sedative during percutaneous carotid artery stenting in a patient with severe chronic obstructive pulmonary disease. Minerva Anestesiol 2009;75:668-71.

4. Bekker AY, Basile J, Gold M, Riles T, Adelman M, Cuff G, et al. Dexmedetomidine for awake carotid endarterectomy: Efficacy, hemodynamic profile, and side effects. J Neurosurg Anesthesiol 2004;16:126-35.

5. Varma MK, Price K, Jayakrishnan V, Manickam B, Kessell G. Anaesthetic considerations for interventional neuroradiology. Br J Anaesth 2007;99:75-85.

6. Jalonen J, Hynynen M, Kuitunen A, Heikkila H, Perttila J, Salmenpera $\mathrm{M}$, et al. Dexmedetomidine as an anesthetic adjunct in coronary artery bypass grafting. Anesthesiology 1997;86:331-45.
7. Bloor BC, Ward DS, Belleville JP, Maze M. Effects of intravenous dexmedetomidine in humans. II. Hemodynamic changes. Anesthesiology 1992;77:1134-42.

8. Mlekusch W, Schillinger M, Sabeti S, Nachtmann T, Lang W, Ahmadi $\mathrm{R}$, et al. Hypotension and bradycardia after elective carotid stenting: Frequency and risk factors. J Endovasc Ther 2003;10:851-9.

9. Talke P, Li J, Jain U, Leung J, Drasner K, Hollenberg M, et al. Effects of perioperative dexmedetomidine infusion in patients undergoing vascular surgery. The Study of Perioperative Ischemia Research Group. Anesthesiology 1995;82:620-33.

10. Willigers HM, Prinzen FW, Roekaerts PM, de Lange S, Durieux ME. Dexmedetomidine decreases perioperative myocardial lactate release in dogs. Anesth Analg 2003;96:657-64.

\begin{tabular}{|l|l|}
\hline \multicolumn{2}{|c|}{ Access this article online } \\
\hline Quick Response Code: & Website: \\
\hline & www.jnaccjournal.org \\
\cline { 2 - 3 } & \\
\hline
\end{tabular}

